\title{
Fulfilling the Demand for Workplace Communication Skills in the Civil Engineering Industry
}

\author{
Masadliahani Masduki* and Normah Zakaria
}

Faculty of Technical and Vocational Education, Universiti Tun Hussein Onn Malaysia, 86400 Parit Raja, Johor, Malaysia

\begin{abstract}
Human resources today must be nurtured with the skills needed at the workplace in preparation for future challenges. Many engineering graduates nowadays are facing difficulties in adapting themselves to the workplace. They are highly dependent on academic qualifications and underestimate the need for skilled workers who are not only technically proficient but have high competencies of soft skills, especially communication skills. The ability of graduates to communicate effectively can have a significant impact on their career development. Therefore, technical graduates need to equip themselves with knowledge of their future workplace's communication needs. The objective of this study is to qualitatively explore the elements of communication skills demanded at the civil engineering workplace. Five participants consisting of experts from academia and industries were involved in semi-structured interviews. Data were hand-transcribed and analysed. Four themes emerged from the data and identified as oral

ARTICLE INFO

Article history:

Received: 11 July 2020

Accepted: 8 October 2020

Published: 25 December 2020 communication, written communication, interpersonal communication, and visual communication. Thirty-four sub-themes appeared from the analysis and have been discussed accordingly.
\end{abstract}

DOI: https://doi.org/10.47836/pjssh.28.4.32

E-mail addresses:

adliq@yahoo.com (Masadliahani Masduki)

norma@uthm.edu.my (Normah Zakaria)

*Corresponding author 


\section{INTRODUCTION}

The main issue and challenge in the Industrial Revolution 4 (IR4) is the mismatch of graduates' skills and knowledge with the demands of the industry in which the mismatches include good social and communication skills (Department of Polytechnic and Community College Education, 2018). Communication is a medium for conveying information and as a tool to get decisions, especially during discussions regarding organisational duties and policies (Quintero et al., 2019). Proper communication can have a significant impact on productivity and work quality. Communication generates productivity because individuals interact and work together to achieve the organisation's goals (Maciulyte-Sniukiene \& Butkus 2020).

In the civil engineering industry, communication skills have been identified as a critical job skill, especially for recruitment purposes. Yusof et al. (2018) argued that a career in engineering relied heavily on communication skills because effective communication between employees was crucial and became the success factor of a project at the construction site. Yusof and Misnan (2019) argued that communication was among the crucial elements in terms of safety at construction sites. Various approaches need to be modified to ensure that safety culture can be socialised in the construction industry through effective communication systems.

A career in engineering is highly dependent on communication skills. According to Ceric (2010), excellent communication between employees is essential for a project's success. In contrast, poor communication is one of the most common project risks. Communication in construction projects is a multifaceted phenomenon that encompasses various disciplines, various levels of the organisation, and various perspectives and interpretations where participants need to collaborate, share, consolidate, and integrate large amounts of information to realise project objectives (Ceric, 2010).

Abdullah (2016) emphasised that in addition to technical education, students should prepare for $21^{\text {st }}$-century career skills where they needed to equip themselves with a wide variety of skills, both technical and non-technical skills. Among the nontechnical skills that the industry desperately needs are workplace communication skills. Communication skills are an element of soft skills that students need to master because excellent communication skills ensure a high degree of self-confidence among students in their field after graduation (Carter et al., 2016). Therefore, to compete in the industry of the 21 st century, university education today needs to assist students to develop communication skills that are similar to the communication used at work (Bhattacharyya, 2018).

Workplace communication skill is pivotal for students to achieve their career development goals. Opinions and information can only be conveyed effectively through excellent communication skills. Previous studies have shown that engineering graduates are unable to meet 
their workplace communication needs (Kovac \& Sirkovic, 2017; Lenard \& Pintarić, 2018). A study by Saleh and Murtaza (2018) found that communication skill was the most crucial skill reported by the industries, but most engineering graduates lacked this skill. This study is supported by Mustapha et al. (2014), who reported that most employers found that the greatest weakness of engineering graduates was the lack of communication skills.

\section{LITERATURE REVIEW}

There is ample evidence from past studies indicating that communication problems are a global issue faced by most students and graduates. According to Danielewicz-Betz and Kawaguchi (2014), 88\% of engineering students in Japan have poor communication skills. Rajprasit et al. (2015) found that engineering students in Thailand had a low level of English language communication skills. The industries in the United States reported that $52 \%$ of engineering graduates had low levels of workplace communication skills (Kirkpatrick, 2011). In Malaysia, $81 \%$ of companies said that the major weakness of most graduates is poor workplace communication skills (Ibrahim $\&$ Mahyuddin, 2017). These results are similar to those reported by the Department of Industrial Training (2013), which found that communication in English was the weakest aspect of polytechnic engineering students during their industrial training.

According to the study of Husain et al. (2015), the communication skills of polytechnic engineering students are frail and need to be improved, especially in terms of oral presentation. This study is supported by the Department of Polytechnics and Community college Education (2018), which reported that $58.3 \%$ of the $59.4 \%$ unemployed polytechnic graduates in 2016 required additional training in communication skills, especially in English. Based on industrial surveys, the common problems faced by civil engineering graduates are poor oral communication skills, inability to understand questions, and lack of interaction skills (Saleh \& Murtaza, 2018). These reports indicated that the communication skills of engineering students need to be improved before they enter the world of work.

Communication problems often occur in a civil engineering environment. Among the issues listed are failure to hear correctly, inability to give and receive correct orders, error in transferring non-verbal cues, failure to communicate well to others, lack of control, limited communication skills in information technology, and false communication of information (Misnan et al., 2009). The problem of communication in the workplace is due to the failure of graduates to develop the current needs of communication skills (Saleh \& Murtaza, 2018).

Students should develop relevant communication skills that are applicable in the industry while they are still studying so that they become effective in the workplace. This is because students' ability to communicate effectively has a significant impact on their future career development. 
However, most students underestimate the importance of communication skills in the workplace and consider technical skills to be sufficient for their career preparation (Mangkau, 2012). Lenard and Pintarić (2018) held the view that employers often complained that local graduates were proficient in technical skills but lacked practical communication skills.

Workplace communication skills can be explained through communication theories. Thus, the use of genre theory and interpersonal communication theory in this study helps us to develop a deeper understanding of workplace communication skills.

\section{Genre Theory}

Humans use genres to simplify their life, to meet expectations (goals), and to save time. Genre has the power to aid or hurt human interaction, to facilitate communication or to deceive, to enable one to speak, or to prevent someone from saying something different (Gaffney, 2010). Genre does not exist separately from the person who uses it; it is created through interactions where dynamic reciprocal relationships exist between genres and communities and are emphasised in the genre's ability to influence the actions of others in the community (Devitt, 2009). In the field of civil engineering, genre evolves through interactions between employees, employees with leaders, employees with clients, and vice versa.

Genres do not exist in humans and must be studied. As students learn about genre through their exposure, they also learn about what is expected from them in the discipline of their choice. Genre represents a complex understanding of communication, which must be learned in order for students to fully engage in the chosen discipline (Gaffney, 2010). The oral and written genres are where students learn about the rhetorical context in which they interact. When engineering students decide on different construction procedures, they constructively develop an understanding of engineering.

Any theme can appear in any genre (Bordwell, 1989). In engineering, communication genres such as team presentations, project progress reports, and group decision-making may be relevant genres to help students learn to explain technical material to the general public in a language they can understand (Dannels, 2001). Genres provide specific meaning and functionality to the communities in which they exist. The genres used in the workplace need to be exposed to students at institutions of higher learning so they can become competent in the workplace (Gaffney, 2010).

It can be concluded that genre is a communication event that takes place in a particular situation to achieve the desired communication goal where the genre represents the elements of communication used in a social setting. Therefore, genre theory is a comprehensive theory and corresponds to the communication skills required in a civil engineering workplace because it emphasises the elements of communication that need to be used in a social place (workplace). According to Giltrow (2002), genre creates categories to promote 
organisations. In the workplace situation, genre theory classified communication into a few genres and sub-genres. In this study, genre explains the communication events (sub-genres) in the workplace of civil engineering which are grouped into the oral genre, written genre, and visual genre.

\section{Interpersonal Communication Theory}

Interpersonal communication occurs when people begin to exchange ideas and thoughts with each other (Dainton \& Zelley, 2017). Interpersonal communication is a form of communication in which individuals communicate their feelings, beliefs, emotions, and information openly with other people, whether verbally or non-verbally (Pfeiffer \& Jones, 1974). Interpersonal communication is not just about what is being said, but also about how it is said, how body language is used, and how facial expressions are presented. In short, communication between two people is referred to as interpersonal communication. Interpersonal communication skills can be enhanced with practice, knowledge, and feedback (Pfeiffer \& Jones, 1974). Interpersonal communication occurs when two people are in the same place and aware of each other's presence (Dainton \& Zelley, 2017).

There are five components of effective interpersonal communication according to Pfeiffer and Jones (1974): (i) adequate self-concept, which is the most important factor influencing communication with others; (ii) the ability to be a good listener; (iii) the ability to express ideas and ideas clearly, which many people find difficult to do; (iv) dealing with emotions, especially anger, and expressing them in a constructive manner; and (v) willingness to disclose to others honestly and freely. Interpersonal communication in the workplace is pivotal to ensure a conducive and healthy working environment.

\section{Problem Statement}

Previous research reported a gap in communication failure in the workplace and in higher institutions whereby the percentage of communication failure in higher institutions was different compared to the percentage of communication failure in the industry (Bhattacharyya et al., 2009; Donnell et al., 2011; Saleh \& Murtaza, 2018). Thus, the industry has recommended higher institutions to provide students with communication skills that are in line with the communication needs in the workplace (Bhattacharyya et al. 2009; Donnell et al., 2011; Hudin et al., 2018).

Despite the emphasis on communication in the workplace, few studies have examined the relevant elements of workplace communication that students need to master before they enter the world of work. Furthermore, there are gaps identified by the industry that indicate the need for more studies in this area. Most studies in the area of workplace communication have only focused on certain constructs. For instance, Bhattacharyya (2018), Bhattacharyya and Zainal (2015), and Darling and Dannels (2017) emphasised the importance of oral communication in the workplace. 
Moore and Morton (2017) and Knoch et al. (2016) emphasised writing demand in the workplace. The work by Chan (2019) highlighted the importance of English in oral and written communicative events at the workplace, while Omar et al. (2012) included interpersonal communication in soft skills demanded by employers. Moreover, most of the studies investigated workplace communications in various other areas without paying much attention to the civil engineering industry.

In order to extend our knowledge of current engineering graduates' workplace communication skills, this study will explore the communication skills demanded at civil engineering workplaces qualitatively.

\section{METHOD}

This study aims to explore the workplace communication skills needed by the civil engineering graduates in Malaysia to fulfil the communication demands of the industry. To accomplish this objective, semi-structured interviews were carried out to attain an understanding from the perspective of academic professionals and industry experts.

\section{Interview Protocols}

The review of the interview protocol was first done with the first author's supervisor, who is a senior lecturer in a local university. Then, the interview protocol was examined thoroughly by three experts. The first expert was a senior lecturer from the Faculty of Technical and Vocational Education in a public university in Malaysia with more than ten years of experience in qualitative research. The second expert was the Head of the Department of Civil Engineering in a Malaysian polytechnic, with over ten years of experience in civil engineering. The third expert was the Head of the Department of Engineering from the Faculty of Technical and Vocational Education in a public university in Malaysia who had more than ten years of experience in career development.

Due to the objective of the study which was to explore the workplace communication skills, the interview protocol was more to inductive probing questions like, "Can you explain the types of communication that are much needed in the civil engineering workplace?" and "How are these communications used in the workplace, whether in the office or on a construction site?"

\section{Participants}

There were five respondents (three academic professionals and two industry experts) involved during the one-on-one in-depth interview sessions:

i). Two experts in the civil engineering industry with at least ten years of experience in the field. These two experts are skilled in training employees and accepting students to undergo industrial training in their company.

ii). Two liaison and industrial training officers with at least five years of experience. iii). A senior lecturer cum head of the civil engineering department at a polytechnic with over ten years of experience. 
These participants were chosen as the respondents of this study because of their experiences in their fields, whereby they could respond to the interview questions with various inputs according to their experiences.

\section{Data Collection}

The interviews took around 40 minutes to one hour. All conversations were recorded and transcribed to obtain the constructs of communication skills for the engineering workplace. Then, participants were given their interview transcripts to review and approve the details they mentioned during the interview session.

\section{Analysis}

This study used the three steps of qualitative analysis proposed by Miles and Huberman (1983), which consisted of i) data reduction, ii) data display, and iii) making and verifying conclusions. During data reduction, data is converted into text form and coded to form categories and themes. Then, the categories and themes were arranged in the form of tables during data display. The final step in this qualitative data analysis involved the interpretations of the results by the researcher.

\section{RESULTS}

This section summarises interesting discoveries gained from the interview sessions. Four significant themes appeared from the transcribed data and categorised into oral communication, written communication, interpersonal communication, and visual communication. There were 34 sub-themes of communication skills identified from the interview sessions with five experts, concerning the civil engineering workplace (Table 1).

Table 1

Elements of civil engineering workplace communication obtained from the interviews

\begin{tabular}{lll}
\hline No. & Civil Engineering Workplace Communication & Frequency \\
\hline \multicolumn{2}{l}{ Oral Communication } & 3 \\
1. & Oral presentation & 5 \\
2. & Meetings & 3 \\
3. & Speaking in English & 2 \\
4. & Telephone conversation & 4 \\
5. & Briefing & 4 \\
6. & Giving/receiving instructions & 3 \\
7. & Discussion & 1 \\
8. & Asking questions & 3 \\
9. & Express idea & 5 \\
10. & Giving respond & \\
\hline
\end{tabular}


Table 1 (Continued)

\begin{tabular}{|c|c|c|}
\hline No. & Civil Engineering Workplace Communication & Frequency \\
\hline \multicolumn{3}{|c|}{ B. Written Communication } \\
\hline 11. & E-mail/ letter & 2 \\
\hline 12. & Writing in English & 2 \\
\hline 13. & Report & 5 \\
\hline 14. & Memo & 3 \\
\hline 15. & Note taking & 1 \\
\hline 16. & Tender & 2 \\
\hline 17. & Documentation & 2 \\
\hline 18. & Social media & 4 \\
\hline 19. & Mathematical skill writing & 2 \\
\hline \multicolumn{3}{|c|}{ C. Visual Communication } \\
\hline 20. & Marketing (brochure/advertisement) & 1 \\
\hline 21. & Technical drawing & 5 \\
\hline 22. & Illustration/ photo/picture & 1 \\
\hline 23. & Charts & 2 \\
\hline 24. & Schedule/ table & 4 \\
\hline 25. & Catalogue & 2 \\
\hline 26. & Specification & 3 \\
\hline 27. & Demonstration & 2 \\
\hline \multicolumn{3}{|c|}{ D. Interpersonal Communication } \\
\hline 28. & Social skill & 1 \\
\hline 29. & Cooperation (teamwork) & 4 \\
\hline 30. & Listening & 2 \\
\hline 31. & Conflict resolution & 2 \\
\hline 32. & Self-concept & 2 \\
\hline 33. & Emotional management & 1 \\
\hline 34. & Non-verbal signal & 2 \\
\hline
\end{tabular}

\section{DISCUSSIONS}

The discussions are based on the four emerged themes, which are oral communication, written communication, interpersonal communication, and visual communication.

\section{Oral Communication}

All participants emphasised that oral communication skill was mandatory for a professional or junior civil engineer because engineers needed to give instructions frequently to the general workers. If they 
could not deliver clear instructions, there would be misunderstandings that could lead to bigger mistakes. This finding is supported by the study by Yusof et al. (2018), who argued that most problems that arose during the implementation of a project at the construction site were due to the shortcomings and weaknesses of the communication system, especially in the dissemination of information and instructions.

"Oral communication is widely used because engineering is more to projects with site supervising work which need to make inspections. So, there is a lot to communicate. Civil engineering graduates are sometimes involved in controlling the general workers in which they become the supervisors. They need to know how to give proper instructions." (P1)

The above statement verifies the genre theory that communication exists through interactions and influences of other people's actions within the community. Participants also suggested that graduates needed to present their ideas clearly and master good phone conversation skills to prevent miscommunications. Bhattacharyya (2018) agreed that technical verbal presentation was one of the communicative events in engineering workplaces, which meant students who were highly competent in presentation skills tended to get employed once they graduated. Meanwhile, Bhattacharyya and Zainal (2015) in their study found that telephone conversation was a common practice of workplace communication.

"As junior engineers, they need to master oral communication. They must know how to communicate in public, make presentations. Phone conversations are a must, right. If you can't talk on the phone, how to communicate with clients or superiors at work to share information or messages? It is really important." (P2)

Graduates also need to be involved in team discussions in which they must ask questions to clarify matters or issues which are unclear. Graduates must have the confidence to ask questions and engage actively in team discussions to develop their generic skills (Zakaria et al., 2018).

"Verbal is widely used, for example, if we want to distribute the works, or ask something that we do not understand, or when we need to check our work with the superior whether it is correct or not." (P3)

"Oral communication. Team discussion happens almost every day. I think, like, we are a small company, we have many workloads, so if they want to learn more, they have to be proactive. They have to ask what they can do, what they can learn." (P4)

Participants in this study revealed that briefings conducted during toolbox meetings were vital and engineers who attended these meetings must respond appropriately to better understand the topics discussed. 
"...thus, listening and giving response are important.” (P4)

"Briefing. We must have toolbox meetings every day, so verbal is very important... We cannot just sit and listen during meetings or briefing that we should respond something. If not, then we might come out with the wrong work." (P5)

Four participants highlighted the importance of speaking in English, especially for those working with big companies as English was the international language, and they needed to engage with people from different races including foreigners. Previous research by Chan (2019), Saleh and Murtaza (2018), and Zahari et al. (2016) also found that engineering graduates who spoke fluent English could positively develop their careers and were able to compete in the industry.

"In terms of language, if it is a big company, English is essential, so it depends on the company." (P1)

"If you want to become an engineer, you must speak good English.” (P3)

"Then, speaking in English is vital because sometimes our client is a GLC client whose culture is in English like UEM." (P4)

"What I can see here is that English is extremely important. If you want to work with a private company, you need to communicate with all staff of different races like Chinese and Indians. Moreover, sometimes we are dealing with an overseas company so we must speak full English." (P5)

\section{Written Communication}

Our findings show that written communication is a part of the genre theory, which explains that genres are derived through contexts or situations combined with forms of communication. All five participants highlighted the importance of written communication skills in the civil engineering workplace. From the five, four participants were concerned about writing through social media (WhatsApp). Some of the benefits of writing using WhatsApp, according to the participants, are i) work, tasks, and instructions can be distributed within seconds; ii) easy to manage the employees/workers; and iii) information can be communicated in time, outside office hours or without the need to wait for face to face meetings. This finding is supported by the study by Turner et al. (2010), which argued that instant messaging provided a medium for collaboration and idea-sharing within the workplace environment.

“Mmm ... Whats App. What kind of communication is this? Written communication. It is important right now. Anything we use WhatsApp. Fast, like... instructions." (PI)

"WhatsApp is not just important. It is very important. WhatsApp is just like we sit in a control room. The management using WhatsApp group or 'pm tepi' (personal message). Even all information is 
communicated to all the subordinates via the WhatsApp group. Quick and too fast." (P2)

"Then, short instruction is necessary because I noticed that when I want to check the drawings or specs (specifications), but I am outside like at the sites, I need to use WhatsApp." (P4)

"WhatsApp group now is used in work. This social app group is a social media platform, but now people are using it for work, so we cannot avoid that, and we have to act professionally." (P5)

Participants in this study also talked about the importance of writing in English, which was an advantage for graduates if they worked in big companies. They suggested that reports, which included progress reports and general reports, letters, and e-mail, should be written using the lingua franca. The study by Chan (2019) found that e-mail, minute, and report writing were frequent written communication events in the workplace, which needed to be done in English even in non-native countries because it was the international language. Yusuf et al. (2018) argued that English writing skills were an important element in today's global workplace, especially in writing memos, e-mails, notices, minutes and agendas, contract documents, reports (technical, daily, problem reports), and contracts.

"One more thing, written ... even to reply letters, e-mails, are all in English, so if they can write in English, it is an advantage." (P4)
"They need to master written communication skills. It is for official e-mail or memo, or letter. Indeed, fully English, even reporting all fully in English." (P5)

Participants also mentioned tender writing, which happened in civil works, writing memos or notices, contract documents, and taking notes using short forms. Furthermore, preparing documents for projects, completing reports, and writing meeting minutes are activities related to writing skills used in the workplace (Saleh $\&$ Murtaza, 2018). Participants also revealed that besides writing reports, e-mails, contract documents, and memos, Mathematical skill was the primary skill that graduates needed to master if they wanted to thrive in the engineering industry.

"Sometimes, they are not involved at the sites (construction), but they do management works, which involve tender writing, reports, and e-mails. In our experience, for civil engineering, they must write a regular report, which is the progress report (project). Sometimes they are involved with... what is the name... quotation ...tender.” (P1)

"We are not going to train them to become secretaries. If they can write and calculate, they can be junior or assistant engineers. Usually, a junior or assistant engineer needs to edit contract documents. Contract documents are standard documents. The only difference is the type of project and taking off. Besides, how to help with our verbal is... what we put on that wall? Memo or notice." (P2) 
"Written. They need to make reports and sometimes need to pass over the works." (P3)

"Then, we must take notes during meetings. It is important to get input from the meeting. Then if you need to make a minute, you can use that note. All instructions must be written in notes so that we will not forget what to do, and we must be good in short forms. " (P5)

\section{Interpersonal Communication}

Participants in this study also mentioned interpersonal communication directly and indirectly. Cooperation, tolerance, and listening skill were perceived as interpersonal communication. These are essential, especially in teamwork, so that they can prevent miscommunication and conflicts. As stated by Azmi et al. (2018), teamwork skills such as cooperation and toleration guaranteed engineering graduates could function effectively both individually and in teams. Lenard and Pintarić (2018) proposed that active listening was vital as it was a tool to understand and interpret oral and non-verbal communication.

"Interpersonal is also crucial, like... cooperation. Then, listening skill, be a good listener among colleagues. " (P1)

"Interpersonal. Cooperation is important, and then toleration" (P4)

Social skill is also vital in the workplace because graduates need to mix around and involve themselves in various interactions, especially when working in teams. Fareen
(2018) agreed that social skills like understanding others, developing rapport, and team support were crucial interpersonal skills in a workplace. Hess et al. (2016) suggested that empathy and care in social skills were valuable in building relationships, trust, and respect at engineering workplaces.

"Okay, and then, environment. Social. Yes, social. To me, social is very important... what we call it? Interpersonal ...yes, interpersonal. In terms of body language, facial expressions when talking to people. They are all interpersonal." (P2)

"Interaction with staff... avoid sharing personal matters, need to show positive communication and avoid the negative one...Interpersonal.” (P3)

"We work with our superior, and we work with the general workers. So, our interactions with our subordinates and our communication with our superiors are very important." (P5)

Additionally, non-verbal communication, such as body language and facial expressions, is considered as interpersonal communication by a participant (P3). According to the participant, non-verbal communication is crucial to avoid misunderstanding. Lenard and Pintarić (2018) argued that non-verbal communication was a clue about a person's feelings or intentions. Other than that, emotion and self-concept also played essential parts in this kind of communication skill. This study is in line with the study by Masek and Masduki (2017), who found 
that a low level of self-concept and being emotional would affect skill performance.

One participant (P5) suggested conflict management as an interpersonal skill without mentioning the construct directly. This finding supports the study by Kovac and Sirkovic (2017), who justified that the skill to resolve conflict was desirable in a workplace in order to become a productive team member. According to Mehrabian (2008), 7\% of individual communication is verbal communication that contains content and meaning, 38\% is non-verbal communication, such as voice, intonation, and tone, while $55 \%$ of communication contains body language communication.

"That's why I said that the tone of voice is important when we mix with others so that there is no misunderstanding. Sometimes we are emotional, but we are not impolite, but people think we are rude. Then, selfconfidence is important. They need to reveal their talent to express their ideas." (P3)

"When there is a problem or conflict, we need to find the solution, to see the ideas how we can solve it." (P5)

The above statements show that the interpersonal communication theory is the best theory to explain workplace communication, which not only involves speech, but may also be explained by gestures, expressions, or body language (non-verbal).

\section{Visual Communication}

Civil engineering and visual communication cannot be apart. In civil engineering organizations, visual communication is particularly important in engineering presentations and drawings where it needs to be well understood in order to avoid misinformation, misrepresentation of tasks, and misunderstandings. This can be proven by statements from the participants of this study, although three participants (P2, P4, P5) did not mention the core skill directly. In the field of civil engineering, genres such as drawing plans are intended to provide guidance and information to engineers, technicians, and workers on important things that need to be done on the construction site, including materials that should be used along with the right specifications. Thus, plan and drawing are the most revealed elements of visual communications in this study.

According to all participants, civil engineering graduates must have the ability to read and draw plans in order to build the exact structures, which are their core business. Husain et al. (2015) in their study revealed that polytechnic engineering students must know how to communicate with drawings and to use Auto-CAD as it was a necessary employability skill. Graduates must also be familiar with the specifications used in the plans or drawings. Only one participant did not mention the work schedule, which was pivotal in tracking projects' progress and making sure the project was completed on time. 
"Besides, visual. Graduates must be good at making specifications, schedules, draw and read plans." (P1)

"They communicate with drawings and plans. They must have the ability to read plans and drawings because they need to know how to transfer the drawings to sites." (P2)

"Graduates need to master the work schedule because once they work, they need to supervise practicum students and become supervisors. They also need to be good at drawing, know how to draw, and read the drawing, AutoCAD. Then, they should know how to take pictures and make reports. These are what we call? Image or what? Visual." (P3)

"I think for construction, we are dealing with structures, so they need to prepare $B Q$, catalogue, and drawing, because even though we are talking about the same things, but others' perceptions are different. The work schedule is important for us to check our progress." (P4)

"If you want to manage projects, you need to know how to read and draw plans. You must master the standards. Assistant or junior engineers should manage the project based on the work program (work schedule)." (P5)

One participant (P2) mentioned the importance of demonstration, which was a useful tool to show how to perform specific tasks at the site to the general workers. Demonstrations are one of the best and effective methods to show others how to perform a task or skill (Selamat et al., 2012). Other than that, respondent P5 stated that graduates needed to have the skill of referring to the catalogues to make sure the exact materials were used in the project.

"Besides, we need to bring samples. Sometimes the general workers do not know what we want, for instance, to bend iron. So, let us bring some iron, and do the bending in front of them. Demonstration... yes, demonstration." (P2)

"Another example is, to make piling, you need to know how to refer to the catalogue in order to approve the supplier." (P5)

Respondent P3 in this study added the skill in making brochures as a valueadded skill for graduates who worked with developers. Yusuf et al. (2018) emphasised that designing advertisements or brochures as one of the essential skills that should be done in English. Besides that, charts are used as a project's schedule (Gantt chart) and during presentations as a tool that helps to support the verbal explanation.

"Sometimes they need to make brochures because they are multitasking, especially if they work with developers." (P3)

"Usually, there are presentations, maybe using PowerPoint, or present using charts... Charts are not necessarily for presentations. Sometimes it is necessary to create a Gantt chart or flow chart for a project." (P1) 


\section{CONCLUSION}

This study has shown that oral communication is the most widely needed communication skill for civil engineering graduates, whereas written communication is compulsory in the workplace. Interpersonal communication, although it seems to be neglected by many graduates, is a highly demanded communication skill by the industry. Civil engineering graduates and visual communication cannot be separated because the field depends tremendously on drawings and plans to manage projects. Both at the individual and team level, graduates will find it challenging to work in the industry if they do not develop mutual agreement through communication to support their work activities. Although there are communication courses for students, these are mainly focused on communication skills at the higher learning institutions and do not pay full attention to the workplace communication skills that students will use during their industrial training and when they join the industry after graduation.

The findings of this study have a few important implications for future practice. Universities and colleges should synchronise the communication courses to the demands of the industry and provide a workplace learning environment so that students can effectively learn workplace communication skills in a more practical way. The communication courses for engineering students should not only include oral and written communication but need to incorporate interpersonal and visual communication, which focuses on all the workplace communication elements mentioned in the finding of this study.

\section{Limitations of the Research}

Due to the small number of participants in this study, the researchers could not make any generalisation about the experts' perceptions regarding workplace communication skills. Notwithstanding the relatively limited sample, this work offers valuable insights into the demands of the industry concerning civil engineering graduates' communication skills at the workplace.

\section{Recommendation for Future Research}

Future research should investigate workplace communication skills with a more significant number of participants, both qualitatively and quantitatively. The present study lays the groundwork for future research into the effectiveness of communication courses at higher education institutions from the perspective of employers to meet the demand of the labour market.

\section{ACKNOWLEDGEMENT}

This study is a part of the first author's doctoral dissertation at Universiti Tun Hussein Onn Malaysia (UTHM) under the supervision of Dr. Normah Zakaria.

\section{REFERENCES}

Abdullah, N. S. (2016). Life and career skills among TVET students in polytechnics in Malaysia. Penang, Malaysia: Universiti Sains Malaysia.

Azmi, A. N., Kamin, Y., \& Noordin, M. K. (2018).

Competencies of engineering graduates: What 
are the employer's expectations? International Journal of Engineering \& Technology, 7(2.29), 519-523. https://doi.org/10.14419/ijet. v7i2.29.13811

Bhattacharyya, E., Nordin, S. M, \& Salleh, R. (2009). Internship students' workplace communication skills: Workplace practices and university preparation. International Journal of Learning: Annual Review, 16(11) 439-452. doi:10.18848/1447-9494/CGP/V16I11/46740

Bhattacharyya, E., \& Zainal, A. Z. (2015). What do students and engineers have to say about communicative competence in technical oral presentations? Pertanika Journal of Social Sciences and Humanities, 23(S), 123-142.

Bhattacharyya, E. (2018). Stakeholders perspective on communicative competence in industry 4.0: Walk the talk of informative technologists. SHS Web of Conferences, 53, 03001. https://doi. org/10.1051/shsconf/20185303001

Bordwell, D. (1989). Historical poetics of cinema. The Cinematic Text: Methods and Approaches, 3, 369-398.

Carter, D. F., Ro, H. K., Alcott, B., \& Lattuca, L. R. (2016). Co-curricular connections: The role of undergraduate research experiences in promoting engineering students' communication, teamwork, and leadership skills. Research in Higher Education, 57(3), 363-393. https://doi. org/10.1007/s11162-015-9386-7

Ceric,A. (2010). The impact of asymmetric information on communication risk in construction projects: Project managers' perceptions. In Engineering Project Organizations Conference, California, USA. Retrieved November 11, 2018, from https://bib.irb.hr/datoteka/609927.EPOC_20102011-2012_June_7.pdf

Chan, C. S. C. (2019). Long-term workplace communication needs of business professionals: Stories from Hong Kong senior executives and their implications for ESP and higher education.
English for Specific Purposes, 56, 68-83. https:// doi.org/10.1016/j.esp.2019.07.003

Dainton, M., \& Zelley, E. (2017). Explaining theories of group communication. In Applying communication theory for professional life (4th ed.). California, USA: Sage Publications.

Danielewicz-Betz, A., \& Kawaguchi, T. (2014). Paper preparing engineering students for global workplace communication: Changing the Japanese mindsets. International Journal of Engineering Pedagogy, 4(1), 55-69. https://doi. org/10.3991/ijep.v4i1.3297

Dannels, D. P. (2001). Time to speak up: A theoretical framework of situated pedagogy and practice for communication across the curriculum. Communication Education, 50(2), 144-158. https://doi.org/10.1080/03634520109379240

Darling, A. L., \& Dannels, D. P. (2017). Practicing engineers talk about the importance of talk: A report on the role of oral communication in the workplace. Communication Education, 4523(June), 1-16. https://doi. org/10.1080/03634520302457

Department of Industrial Training. (2013). The communication skills mastery of industrial training students of Kuching Sarawak Polytechnic based on the evaluation by the firms. Retrieved December 2, 2018, from http://dspace.poliku.edu.my/xmlui/bitstream/ handle/123456789/1508/JOSHUA \%20 TAHAP $\% 20$ KEMAHIRAN \% $20 \mathrm{KOM}$. pdf? sequence $=5 \&$ is Allowed $=\mathrm{y}$

Department of Polytechnic and Community College Education. (2018). Polytechnic information. Retrieved January 27, 2020, from http://www. mypolycc.edu.my/index.php/muat-turun/bukuinformasi/download/5-buku-informasi/7-bukuinformasi-politeknik

Devitt, A. J. (2009). Re-fusing form in genre study. In Genres in the internet: Issues in the Theory of Genre. Philadelphia, USA: John Benjamins Publishing. 
Donnell, J. A., Aller, B. M., Alley, M., \& Kedrowicz, A. A. (2011). Why industry says that engineering graduates have poor communication skills: What the literature says. Paper presented at the ASEE Annual Conference and Exposition, Vancouver, Canada. Retrieved May 6, 2018, from file://C:/ Users/norhafizah\%20abd\%20rani/Downloads/ Engineering_Industry_Communication_final.pdf

Fareen, J. A. M. (2018). Job focus: Revisiting students' communicative needs and industrial demands. Journal of Language and Education, 4(4), 42-53. https://doi.org/10.17323/2411-73902018-4-4-42-53

Gaffney, A. L. H. (2010). Communicating about, in, and through design: A study exploring communication instruction and design students' critique performance. North Carolina, USA: North Carolina State University.

Giltrow, J. (2002). Meta-genre. The rhetoric and ideology of genre. In R. M. Coe, L. Lingard, \& T. Teslenko (Eds.), Strategies for stability and change. Cresskill, USA: Hampton Press.

Hess, J. L., Strobel, J., \& Pan, R. (Celia). (2016). Voices from the workplace: Practitioners' perspectives on the role of empathy and care within engineering. Engineering Studies, 8(3), 212-242. https://doi.org/10.1080/19378629.20 16.1241787

Hudin, N. S., Osman, J., Shokory, S. M., \& Ab Wahid, H. (2018). Service learning in higher education: Evidence from Malaysia. International Journal of Engineering \& Technology, 7(January), 474479. doi:10.14419/ijet.v7i3.30.18361.

Husain, M. Y., Mokhtar, S. B., \& Alias, A. H. (2015). Polytechnic engineering students perceptions of the employability skills: A case study. Advanced Journal of Technical and Vocational Education, 1(2), 25-32.

Mustapha, R., Husain, M. Y., Syed, M. S. A. M., \& Mokhtar, S. B. (2014). Persepsi majikan kejuruteraan terhadap tahap kemahiran empolyabiliti pelajar kejuruteraan institusi teknikal: Satu kajian kes [Engineering employers' perceptions of the level of employability skills of technical institutions engineering students: A case study]. Journal of Science, Mathematics and Technology, 1(2), 41-55. https://doi. org/10.13140/2.1.5118.9120

Ibrahim, D. H. M., \& Mahyuddin, M. Z. (2017). Youth unemployment in Malaysia: Developments and policy considerations. Retrieved November 11, 2011, from https://www.bnm.gov.my/files/ publication/ar/en/2016/cp04_003_box.pdf

Kirkpatrick, A. T. (2011). Vision 2030: Creating the future of mechanical engineering education. Paper presented at the 2011 ASEE Annual Conference \& Exposition, Vancouver, Canada. Retrieved May 16, 2018, from https://peer.asee. org/18870

Knoch, U., May, L., Macqueen, S., Pill, J., \& Storch, N. (2016). Transitioning from university to the workplace: Stakeholder perceptions of academic and professional. Retrieved February 1, 2019, from https://eprints.qut.edu.au/93137/1/ielts online_rr_2016-1.pdf

Kovac, M. M., \& Sirkovic, N. (2017). Attitudes towards communication skills among engineering students. English Language Teaching, 10(3), 111-117. https://doi.org/10.5539/elt.v10n3p111

Lenard, D. B., \& Pintarić, L. (2018). Comparison of employers' and students' perceptions regarding communication skills. Journal of Teaching English for Specific and Academic Purposes, 6(1), 63-82. https://doi.org/10.22190/ jtesap1801063b

Maciulyte-Sniukiene, A., \& Butkus, M. (2020). Impact of information and communication technologies on productivity growth. International Journal of Information Technology and Management, 19(1), 1-18.

Mangkau, I. D. (2012). Penguasaan kemahiran komunikasi dalam kalangan pelajar Universiti 
Tun Hussein Onn Malaysia (UTHM) [The mastery of communication skills amongst Universiti Tun Hussein Onn Malaysia (UTHM) students]. Prosiding Seminar Pendidikan Pasca Ijazah dalam PTV Kali Ke-2. Retrieved May 6, 2018, from https://pdfslide.tips/documents/ prosiding-seminar-pendidikan-pasca-ijazahdalam-ptv-kali-ke-2-.html

Masek, A., \& Masduki, M. (2017). Participation of shy children during the teaching and learning of basic psychomotor skill. Pertanika Journal of Social Science and Humanities, 25(1), 55-66.

Mehrabian, A. (2008). Communication without words. In Communication theory. New York, USA: Routledge.

Miles, M. B., \& Huberman, A. M. (1983). Drawing valid meaning from qualitative data: Toward a Shared Craft. Educational Researcher, 13(5), 20-30.

Misnan, M. S., Ramly, Z. M., Lee, C. K., \& Bakri, A. (2009). Pengurusan projek pembinaan: Kaedah dan keberkesanan komunikasi di tapak bina [Construction project management: Methods and effectiveness of communication on construction sites]. In Management in Construction Research Conference. Penang, Malaysia: Universiti Sains Malaysia.

Moore, T., \& Morton, J. (2017). The myth of job readiness? Written communication, employability, and the 'skills gap' in higher education. Studies in Higher Education, 42(3), 591-609. https://doi.org/10.1080/03075079.20 15.1067602

Omar, N. H., Manaf, A. A., Mohd, R. H., Kassim, A. C., \& Aziz, K. A. (2012). Graduates' employability skills based on current job demand through electronic advertisement. Asian Social Science, 8(9), 103-110. https://doi.org/10.5539/ ass.v8n9p103

Pfeiffer, J. W., \& Jones, J. E. (1974). Structured experiences for human relations training: $A$ reference guide (Vol. 1). San Diego, USA: University Associates.

Quintero, Y. A. R., Sukier, H. B., Capella, J. A. C., \& Molina, R. I. R. (2019). Responsible communication strategies for small and mediumsized enterprises. Opción, 89(2), 1208-1234.

Rajprasit, K., Pratoomrat, P., \& Wang, T. (2015). Perceptions and problems of English language and communication abilities: A final check on Thai engineering undergraduates. English Language Teaching, 8(3), 111-120. https://doi. org/10.5539/elt.v8n3p111

Saleh, N. S., \& Murtaza, S. F. (2018). English language use in Malaysian government and private civil engineering workplaces. International Journal of Education \& Literacy Studies, 6(3), 84-91. http://dx.doi.org/10.7575/aiac.ijels.v.6n.3p.84

Selamat, A., Esa, A., Salleh, B. M., \& Baba, I. (2012). Extra classes effectiveness in smart secondary school, Johore, Malaysia. Asian Social Science, 8(1), 111-118. https://doi.org/10.5539/ass. v8n1p111

Turner, T., Qvarfordt, P., Biehl, J. T., Golovchinsky, G., Back, M., Ave, H., \& Alto, P. (2010). Exploring the workplace communication ecology. User Characteristics and LargeScale Tracking, 10(15), 841-850. https://doi. org/10.1145/1753326.1753449

Yusof, N., \& Misnan, M. S. (2019). Restriction factors to implement safety practices in small grade contractors. International Journal of Built Environment and Sustainability, 6(1-2), 15-21. doi:10.11113/ijbes.v6.n1-2.378.

Yusuf, N. K., Md Yunus, M., \& Embi, M. A. (2018). Workplace writing in L2 experiences among millennial workforce: Learning to write in English. 3L: Language, Linguistics, Literature, 24(1), 145-161. https://doi. org/10.17576/3L-2018-2401-11 
Zahari, S. D. Z., Mohd, Z. A. A., Abu, B. N., Basri, I. S., \& Omar, S. (2016). English language communication needs at workplace as perceived by students. Journal of Science \& Engineering Technology, 3(2), 27-31.

Zakaria, N., Masduki, M., \& Ismail, N. N. (2018). Eliminating shyness through co-curricular activities towards enhancing the career development of engineering students. IOP Conference Series: Journal of Physics, 1049(1), 012057. https://doi.org/10.1088/17426596/1049/1/012057 
